\title{
NUMERICAL OPTIMIZATION OF HELICOPTER ROTOR BLADE DESIGN FOR ACTIVE TWIST CONTROL
}

\author{
A. Kovalovs ${ }^{1}$, E. Barkanov ${ }^{2}$, S.Gluhihs ${ }^{3}$ \\ Institute of Materials and Structures, Riga Technical University, Azenes St. 16-323, LV-1048, Riga, Latvia \\ E-mails: ${ }^{1}$ kovalovs@bf.rtu.lv; ${ }^{2}$ barkanov@latnet.lv; ${ }^{3}$ s_gluhih@inbox.lv \\ Received 24-04-2007, accepted 10-09-2007
}
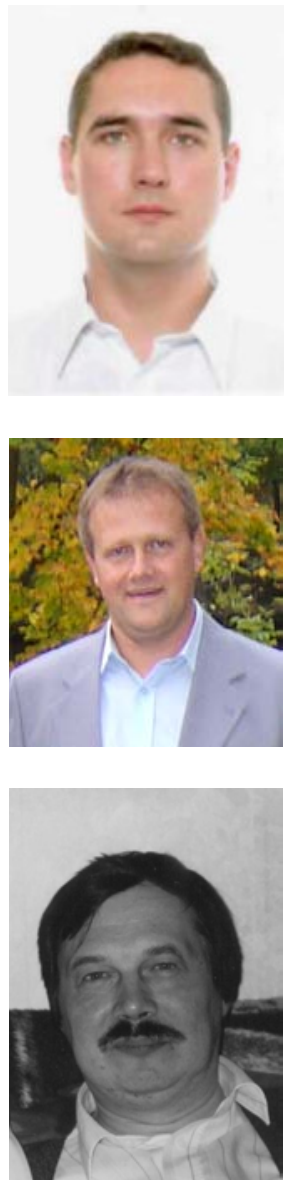

Andrejs KOVALOVS, M. Sc

Date of birth: April 11, 1975

Education: 1996 - Bachelor degree in mechanical engineering, Riga Aviation University; 1997 - Engineer degree in mechanical engineering, Riga Aviation University; 1999 - Masters degree in mechanical engineering, Riga Aviation University.

Experience: Researcher, Institute of Materials and Structures, Riga Technical University

Fields of research: strength of structures, mechanics of composite materials, numerical methods and computer analysis of structures.

\section{Evgeny BARKANOV, Assoc. Prof.}

Date of birth: January 8, 1964.

Education: 1986 -First class diploma from the Faculty of Technical Appliances and Automation, Riga Technical University. 1993 - Doctoral degree Riga Technical University. 2005 - Assoc. Professor Riga Technical University. Experience: Institute of Materials and Structures, Riga Technical University Publications: Author of more than fifty different scientific publications.

Fields of research: strength and dynamics of structures, damping analysis, mechanics of composite materials, numerical methods and computer analysis of structures, optimisation.

Sergejs GLUHIHS, Dr. Sc.eng

Date and place of birth: March 11, 1953, Riga.

Education: 1976 - St. Petersburg Technical University, $\mathrm{PhD}$ in mechanical engineering.

Experience: 1976 - Present - Institute of Materials and Structures, Riga Technical University.

Publications: Author of more than forty different scientific publications.

Fields of research: strength and dynamics of structures, damping analysis, mechanics of composite materials, numerical methods and computer analysis of structures, strength of foam-rubber.

Abstract. The vibration of a helicopter has several different sources, such as the rotor, engine and transmission system. This creates a number of problems with performance, for example poor manoeuvrability, discomfort of the pilot, low fatigue life of the structural components, and, consequently, high operating costs.

At the present time there are in existence various methodologies for vibration reduction, such as higher harmonic control (HHC), individual blade control (IBC), active control of structural response (ACSR), active twist blade (ATB), and active trailing-edge flap (ATF).

The goal of the presented work is the development of an active twist actuation concept based on the application of macro fiber composite (MFC) actuators. These actuators consist of polyamide films with IDE-electrodes. They are glued on the top and the bottom of piezoceramic ribbons and oriented at $\pm 45^{\circ}$ to the spar axis of the rotor blade. The interdigitated electrodes deliver the electric field required to activate the piezoelectric effect in the fibres and this, in turn, creates a stronger longitudinal piezoelectric effect along the length of the fibres. The properties and orientation of piezoelectric actuators cause the MFC actuators to induce shear stresses and thus distribute a twisting movement along the blade.

The design methodology, based on the planning of experiments and response surface technique, has been developed for an optimum placement of macro fibre composite (MFC) actuators in helicopter rotor blades. The optimisation problem for the optimum placement of actuators in helicopter rotor blades has been formulated on the results of parametric study. The investigated helicopter has a rotor blade, which is equipped with NACA23012 airfoil and has a rectangular shape with an active part radius of $1.56 \mathrm{~m}$ and a 
chord length of $0.121 \mathrm{~m}$. The blade also consists of D-spar. This is made of unidirectional fibreglass, reinforced plastic (UD GFRP), a skin made of $\pm 45^{\circ}$ GFRP, a foam core, balancing weight and MFC actuators placed on the top and bottom of the skin. The $3 \mathrm{D}$ finite element model of the rotor blade has been built by ANSYS. The rotor blade skins are modelled with linear layered structural shell elements (SHELL99), balancing weights and foam with 3D 20-node structural solid elements (SOLID186). The spar is modelled with shell and solid elements.

The optimisation results have been obtained for design solutions, connected with an application of active materials, and checked by the finite element calculations.

Keywords: active twist, macro fibre composite (MFC), helicopter rotor blade, optimization.

\section{Introduction}

The vibration of a helicopter has several different sources, such as the rotor, engine and transmission system. This creates a number of problems with performance, for example poor manoeuvrability, discomfort of the pilot, low fatigue life of the structural components, and, consequently, high operating costs.

Traditional helicopter vibration control methods are based on the application of higher harmonic control (HHC) and individual blade control (IBC). However, because of the recent development of smart materials, a new active control technique has begun to be implemented for the control of rotor blade vibration, noise reduction and enhanced performance.

Recently, several active control approaches have been investigated. These have used smart material actuation to achieve individual blade control without the need for complex mechanisms in the rotating frame. The application of such materials for control has resulted in the production of two innovative designs: the trailing edge flap rotor and active twist rotor.

Chen and Chopra did early studies on the concept of an active twist rotor in 1996 [5, 4]. According to their designs, the rotor blade incorporated discrete dual-layer monolithic piezopatch elements embedded at $+45^{\circ}$ under the upper skin and $-45^{\circ}$ under the lower skin of the rotor blade. Experiments were conducted on a two bladed, hinge less rotor with a 6 -foot diameter and built to a $1 / 8$ Freud scale. Different piezoceramic arrangements were analyzed along with different rotation speeds. The maximum tip twists at resonance frequencies were $0.35^{0}$ and $1.1^{0}$.

Later, in 1998, Bernhard and I. Chopra developed an active, on blade vibration-reduction system, which used smart, active blade tips (SABT) and was driven by a piezo-induced, bending-torsion coupled actuator $[3,2]$. The beam was designed specifically to fit within the rotor blade profile and was used essentially as a pure torsion actuator. The beam lay-up was selected so that if the inboard end was clamped, the outboard end resulted in a twist. This twist was measured by the deflection of the SABT. A Mach-scale active twist rotor was fabricated and tested using the SABT concept. The rotating twist amplitudes with SABT are similar to the tip twist amplitudes reported by P. Chen and I. Chopra [12, 10].

In 1998 a new approach to smart materials was adopted by J.P. Rodgers and N.W. Hagood [11, 13]. They attempted to develop an integral, twist-actuated rotor, which would allow for individual blade control. Active fiber composites (AFC) were integrated within a composite rotor blade to induce a twisting movement.
These were active plies oriented at $45^{\circ}$ angles to the blade span in order to induce shear stresses and the distribution of a twisting movement along the blade. A CH-47D blade was designed to a 1/6 Mach-scale and was then fabricated and tested in hover at the MIT hover test facility. Good correlation was obtained between theory and the results of experiments.

The goal of the present work is the development of an active twist actuation concept based on the application of macro fiber composite (MFC) actuators [14, 12].

A macro fiber composite was developed at NASA Langley Research Center. The actuators consist of polyamide films with interdigited electrodes that are glued on the top and bottom of piezoceramic fibres (Fig 1, 2).

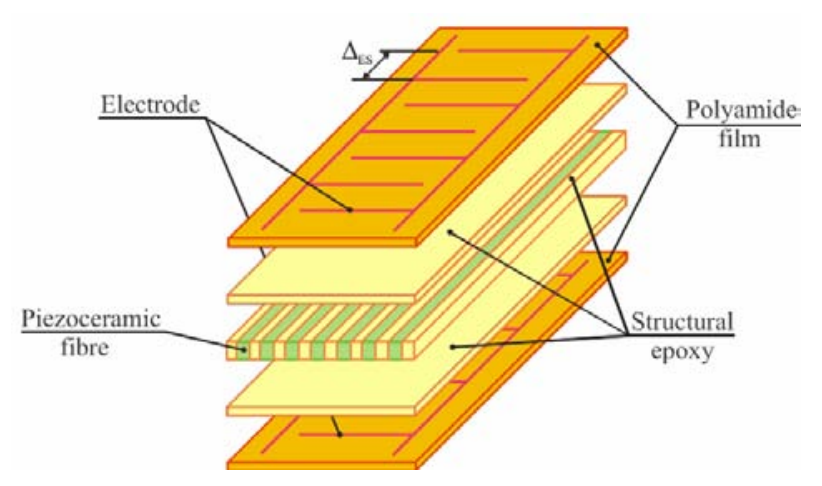

Fig 1. MFC actuator construction

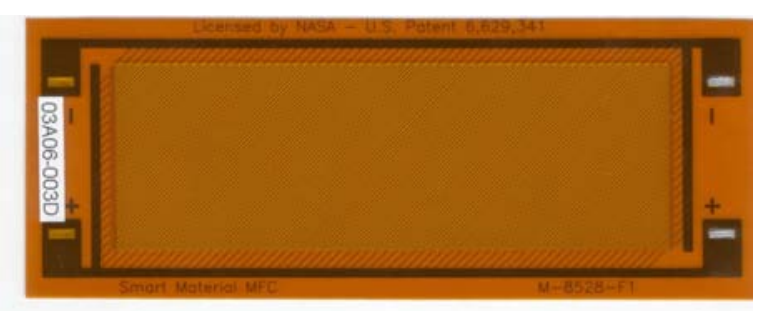

Fig 2. MFC actuator

The interdigitated electrodes deliver the electric field required to activate the piezoelectric effect in the fibers. This then allows for the creation of stronger longitudinal piezoelectric effects along the length of the fibers.

In contrast with MFC, the circular cross-section PZT fibers of the AFC had very little contact area between the interdigitated electrodes and the fibers. This resulted in the transfer of the electric field into the PZT fibers inefficiently. The rectangular PZT fibers of the MFC improved the maximum contact area between the PZT fibers and the interdigitated electrodes and, as a result, increased the angle of twist [10]. 
The aim of the present study is to describe the methodology, based on the planning of experiments and response surface technique, for the optimal design of active rotor blades using MFC actuators. The reason for this is to obtain high piezoelectric actuation forces and displacements with the minimal actuator weight and energy applied. The structural static analysis with a thermal load is carried out to characterize an active twist of the helicopter rotor blade. Design solutions for an application of active materials are studied to estimate the effectiveness.

\section{Helicopter rotor blade}

An investigated helicopter rotor blade is equipped with NACA23012 airfoil and has a rectangular shape with active part radius $R=1.56 \mathrm{~m}$ and chord length $\mathrm{c}=0.121 \mathrm{~m}($ Fig 3$)$.

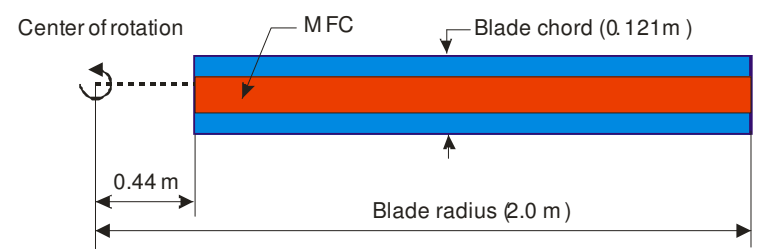

Fig 3. Active part of rotor blade with MFC

This rotor blade consists of D-spar made of unidirectional GFRP (Fiberglass Reinforced Polymer), skin made of $+45^{\circ} /-45^{0}$ GFRP, a foam core, MFC actuators and balancing weight (Fig. 4). The thickness of the GFRP skin layer is $0.125 \mathrm{~mm}$ whilst the thickness of MFC layer is $0.3 \mathrm{~mm}$. The material properties of the rotor blade components are as follows:

- GFRP: $E_{x}=11.981 \mathrm{GPa}, E_{y}=11.981 \mathrm{GPa}, E z=45.166$ $\mathrm{GPa}, G x z=4.583 \mathrm{GPa}, G y z=4.583 \mathrm{GPa}, G x y=1.289$

$\mathrm{GPa}, v_{y z}=0.238, v_{x z}=0.238, v_{x y}=0.325, \rho=2008$ $\mathrm{kg} / \mathrm{m}^{3}$

- Foam (Rohacell $51 \mathrm{FX}$ ): $E=0.035 \mathrm{GPa}, G=0.014$ $\mathrm{GPa}, v=0.25, \rho=52 \mathrm{~kg} / \mathrm{m}^{3}$

- Lead: $E=13.790 \mathrm{GPa}, G=2.000 \mathrm{GPa}, v=0.44, \rho=$ $11300 \mathrm{~kg} / \mathrm{m}^{3}$

- MFC: $E_{x}=30.0 \mathrm{GPa}, E_{y}=15.5 \mathrm{GPa}, E_{z}=15.5 \mathrm{GPa}, G_{x z}$ $=10.7 \mathrm{GPa}, G_{y z}=10.7 \mathrm{GPa}, G_{x y}=5.7 \mathrm{GPa}, v_{y z}=0.4$, $v_{x z}=0.4, v_{x y}=0.35, d_{33}=4.18 \times 10^{-10} \mathrm{~m} / \mathrm{V}, d_{32}=d_{31}=-$ $1.98 \times 10^{-10} \mathrm{~m} / \mathrm{V}, \rho=4700 \mathrm{~kg} / \mathrm{m}^{3}$

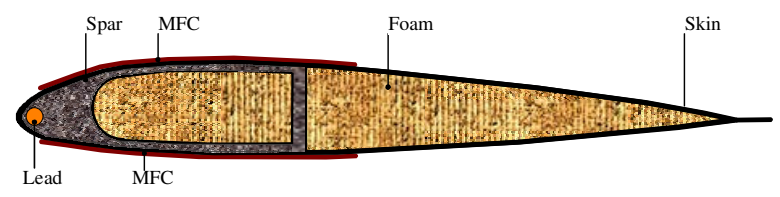

Fig 4. Cross-section of the helicopter rotor blade

\section{Finite element analysis}

The 3D finite element model of the rotor blade is produced by ANSYS (Fig 5). The rotor blade skin and spar "moustaches" are modelled with linear layered, structural shell elements (SHELL99). The spar and foam, however, are produced using 3D 20 node structural solid elements (SOLID186). The clamped boundary conditions are applied from one end-side of the rotor blade.

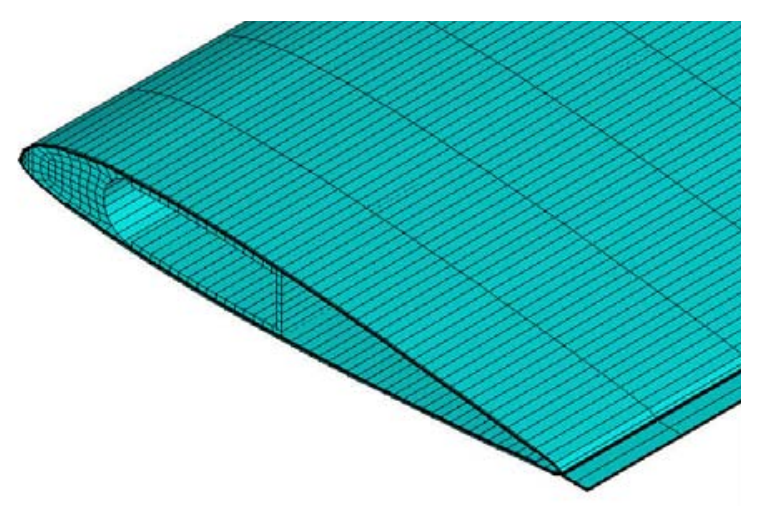

Fig 5. Finite element model of the helicopter rotor blade without foam

The thermal analogy based on the analogy between the piezoelectric effect and thermoelastic effect. An applied electric field is modelled as a thermal load. The correspondence between piezoelectric strain and thermal strain is obtained by taking:

$$
\alpha_{i j}=\frac{d_{i j}}{\Delta_{E S}},
$$

where $d_{i j}$ is the effective piezoelectric constant and $\Delta_{\mathrm{ES}}$ is the electrode spacing taken as $\Delta_{\mathrm{ES}}=0.5 \mathrm{~mm}$.

Then, steady-state thermal analysis is carried out to determine a torsion angle of the rotor blade, static torsion analysis is employed to determine a location of the elastic axis and modal analysis is used to determine the first torsion eigenfrequency of the rotor blade (Fig 6).

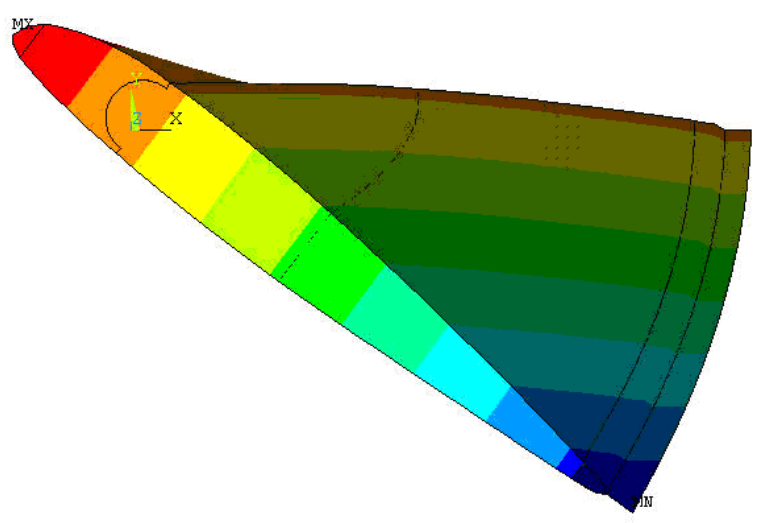

Fig 6. Twist of the helicopter rotor blade

\section{Parametric study}

Before the formulation of the optimisation problem, the parametric study has been carried out with the purpose to decrease a number of design parameters (Fig 7). By doing this the accuracy of the obtained optimal results will be increased. The findings of parametric study have been investigated in previous work [9]. 


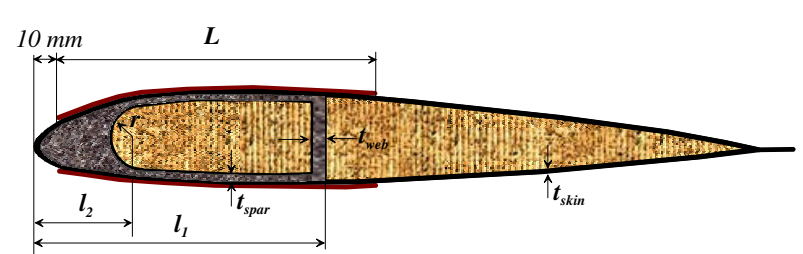

Fig 7. Design parameters of the helicopter rotor blade

The skin thickness is examined as a discrete value design parameter with the step $\Delta t_{(+45 /-45)}=0.25 \mathrm{~mm}$.

The smallest influence has been shown by spar "moustaches" length, web length and web thickness. The influence on the torsional angle of the spar "moustaches" thickness and web thickness together is better than only the spar "moustaches" thickness. The voltage has influence on the strain. But this influence is less than permissible. For this reason, web thickness, web length, voltage and spar "moustaches" thickness have been excluded from the set of design parameters used in this optimisation.

\section{Optimal design}

Due to the large dimensions of the numerical problem to be solved, the non-direct optimisation technique should be applied. Indeed, the application of direct minimisation algorithms and multiple finite element analysis is too expensive from a computational point of view. For this reason, an optimisation methodology is developed employing the method of experimental design and response surface technique.

\subsection{Formulation of optimisation problem}

An optimisation problem for the optimum placement of actuators in helicopter rotor blades has been formulated based on the results of parametric study and taking into account the producer's requirements (Fig 8) [9]:

Design parameters: $\{x\}=\left\{l, t_{\text {skin }}, t_{\text {spar }}, L\right\}$

$16 \leq l \leq 24 \mathrm{~mm}$

$0.25 \leq t_{\text {skin }} \leq 1.25 \mathrm{~mm}$

$0.50 \leq t_{\text {spar }} \leq 2.50 \mathrm{~mm}$

$16 \leq L \leq 100 \mathrm{~mm}$

\section{Constraints:}

$22 \leq y_{c g} \leq 30$

$10 \leq y_{e a} \leq 25$

$m \leq 1.35$

$f_{T 1} \geq 59.15$

where $l$ - spar circular fitting $(\mathrm{mm}), t_{\text {skin }}$ - skin thickness $(\mathrm{mm}), t_{\text {spar }}$ - spar thickness and web thickness together (mm), $L-$ MFC chord-wise length (mm), $y_{c g}$ - location of the centre of gravity $(\%), y_{e a}$ - location of the elastic axis $(\%), m$ - mass of cross-section $(\mathrm{kg} / \mathrm{m}), f_{T 1}$ - first torsion eigenfrequency $(\mathrm{Hz})$. The length of spar is $56 \mathrm{~mm}$ and Voltage is $1000 \mathrm{~V}$.

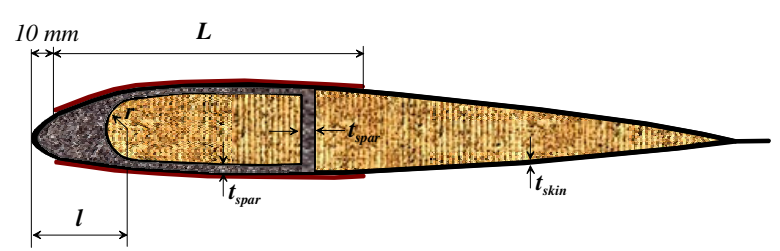

Fig 8. Design parameters

In the previous work the application of active material has been investigated when it is applied on the top of the skin [9].
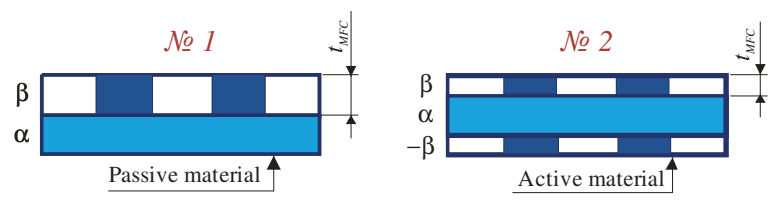

Fig 9. Application of active material

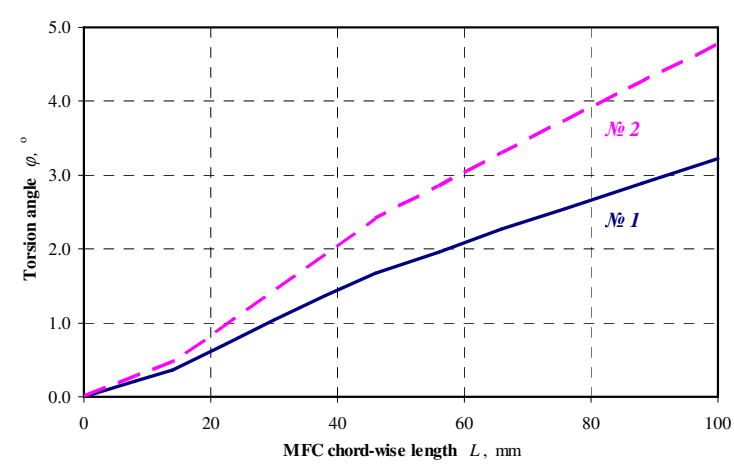

Fig 10. Comparison between applications of active material

Later studies of parametric research for two different applications of the active material have been studied to determine their effectiveness (Fig 9). As can be seen from the graphs, variant 2 is considerably more effective than variant 1 in relation to active twist of the helicopter rotor blade (Fig 10). For this reason, the second variant of application of smart material has been chosen as a solution to the optimization problem, when active materials apply on the top and bottom of skin.

\subsection{Experimental design and FEM simulations}

The program EDAOpt was used for the generation of the experimental design [1]. D-optimal experimental design is formulated for 4 design parameters and 30 experiments. Then, in the points of the plan of experiments, both the structural static analysis with a thermal load and modal analysis are carried out to determine the torsion angles in the rotor blade and the first torsion eigenfrequency respectively. As with additional parameters, a location of the centre of gravity and rotor blade mass are found from the finite element model. Determining the elastic axis location is a more complicated problem and requires a solution to the additional static torsion problem. This involves the 
application of two forces independently from both sides of the sought elastic centre [8].

\subsection{Response surfaces}

At the time of the present study a form of the equation of regression was previously unknown [6]. There are two requirements for the equation of regression: accuracy and reliability. Accuracy is characterised as a minimum of standard deviation of the table data from the values given by the equation of regression. By increasing the number of terms in the equation it is possible to obtain a complete agreement between the table data and the values given. However, it is necessary to note that prediction at the intervals between the table points can be poor. For an improvement of prediction, it is necessary to decrease the distance between the points of experiments by increasing the number of experiments or by decreasing the domain of factors. Reliability of the equation of regression can be characterised by an affirmation that standard deviations for the table points and for any other points are approximately the same. Obviously the reliability is greater for a smaller number of terms of the equation of regression.

The equation of regression can be written in the following form:

$$
y=\sum_{i=1}^{p} A_{i} f_{i}\left(x_{j}\right)
$$

where $A_{i}$ - the coefficients of the equation of regression, $f_{i}\left(x_{j}\right)$ - the functions from the bank of simple functions $\theta_{l}$, $\theta_{2}, \ldots \theta_{m}$, which are assumed as ,

$$
\theta_{m}\left(x_{j}\right)=\prod_{i=1}^{s} x_{j}^{\xi_{m i}}
$$

where $\zeta_{m i}$ is a positive or negative integer including zero. Synthesis of the equation from the bank of simple functions is carried out in two stages: selection of perspective functions from the bank and then step-by-step elimination of the selected functions.

At the first stage all variants are tested with the least square method and the function which leads to the minimum of the sum of deviations is chosen for each variant. On the second stage, the elimination is carried out using the standard deviation

$$
\sigma_{0}=\sqrt{\frac{S}{k-p+1}}, \sigma=\sqrt{\frac{1}{k-1} \sum_{i=1}^{k}\left(y_{i}-\frac{1}{k} \sum_{j=1}^{k} y_{j}\right)^{2}}
$$

or correlation coefficient

$$
c=\left(1-\frac{\sigma}{\sigma_{0}}\right) * 100 \%
$$

where $k$ - the number of experimental points, $p-$ the number of selected perspective functions and $S-$ the minimum sum of deviations. It is more convenient to characterise the accuracy of the equation of regression by the correlation coefficient (Fig 11).

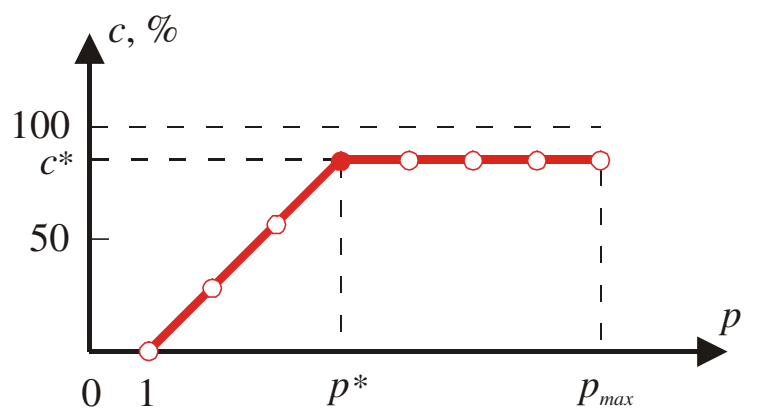

Fig 11. Diagram of elimination for the correlation coefficient

If insignificant functions are eliminated from the equation of regression, a reduction of the correlation coefficient is negligible. If in the equation of regression only significant functions are presented, elimination of one of them leads to an important decrease in the correlation coefficient.

Response surfaces for all behaviour functions have been obtained with the correlation coefficients around 90 $\%$ and higher. They have been verified by the finite element solutions in the points different from the points taken in the plan of experiments. Results of verification are presented in figures 12-14.

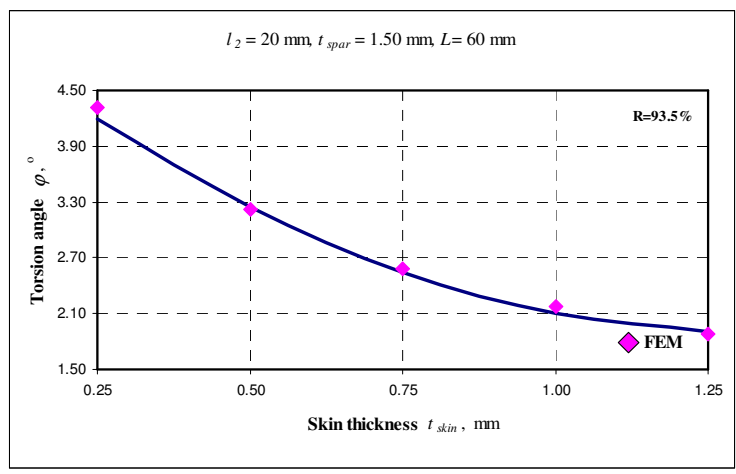

Fig 12. Accordance between approximation function and control points for torsion angle and skin thickness

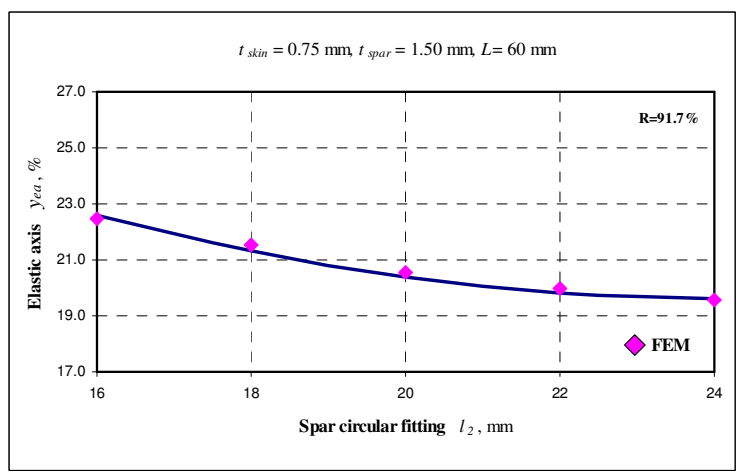

Fig 13. Accordance between approximation function and control points for elastic axis and spar circular fitting 


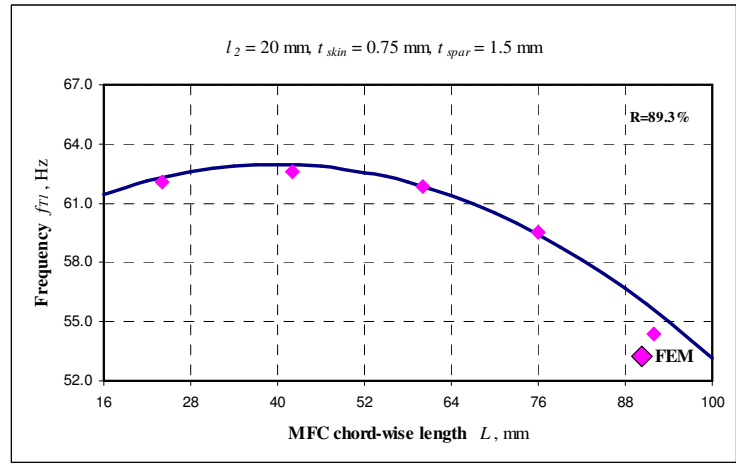

Fig 14. Accordance between approximation function and control points for frequency and MFC chord-wise length

\subsection{Optimisation results}

The non-linear, global optimisation problem executed by the Improved Multistart Random Search using the response surfaces obtained [7]. In the first stage, the design problem has been solved with the purpose of obtaining a maximum torsion angle. The optimisation is given in tables 1-3 together with the finite element solutions obtained in the optimal point. As can be seen in the tables, the difference between finite element and response surface solutions is reasonable.

Table 1. Design parameters

\begin{tabular}{|c|c|c|c|c|}
\hline & \multicolumn{4}{|c|}{ Design parameters } \\
\hline & $\begin{array}{c}l \\
\mathrm{~mm}\end{array}$ & $\begin{array}{c}t_{\text {skin }} \\
\mathrm{mm}\end{array}$ & $\begin{array}{c}t_{\text {spar }} \\
\mathrm{mm}\end{array}$ & $\begin{array}{c}L \\
\mathrm{~mm}\end{array}$ \\
\hline $\begin{array}{c}\text { Response } \\
\text { surfaces }\end{array}$ & 22 & 0.25 & 0.50 & 82 \\
\hline FEM & 22 & 0.25 & 0.50 & 82 \\
\hline
\end{tabular}

Table 2. Constraints

\begin{tabular}{|c|c|c|c|c|}
\hline & \multicolumn{4}{|c|}{ Constraints } \\
\hline & $\begin{array}{c}y_{c g} \\
\%\end{array}$ & $\begin{array}{c}y_{e a} \\
\%\end{array}$ & $\begin{array}{c}m \\
\mathrm{~kg} / \mathrm{m}\end{array}$ & $\begin{array}{c}f_{T 1} \\
\mathrm{~Hz}\end{array}$ \\
\hline $\begin{array}{c}\text { Response } \\
\text { surfaces }\end{array}$ & 29.4 & 18.1 & 1.20 & 59.77 \\
\hline FEM & 29.0 & 17.7 & 1.23 & 58.88 \\
\hline$\Delta \%$ & 1.4 & 2.3 & 2.5 & 1.5 \\
\hline
\end{tabular}

Table 3. Objective function and effectiveness

\begin{tabular}{|c|c|c|}
\hline & $\begin{array}{c}\text { Objective } \\
\text { function }\end{array}$ & $\begin{array}{c}\text { Effecti- } \\
\text { veness }\end{array}$ \\
\hline & $\boldsymbol{\varphi}^{\circ}$ & $\boldsymbol{\varphi} / \boldsymbol{R},{ }^{\circ} / \mathrm{m}$ \\
\hline Response surfaces & 5.39 & 3.46 \\
\hline FEM & 5.39 & 3.46 \\
\hline$\Delta \%$ & 0.0 & 0.0 \\
\hline
\end{tabular}

\subsection{Parametric study}

After optimisation, additional parametric study has been carried out for designer convenience and to investigate the influence of different design parameters on behavioural functions.

The dependencies of the torsion angle on MFC chord-wise length and spar circular fitting, first torsion frequency on MFC chord-wise length, and skin thickness are given in figures $15-17$.

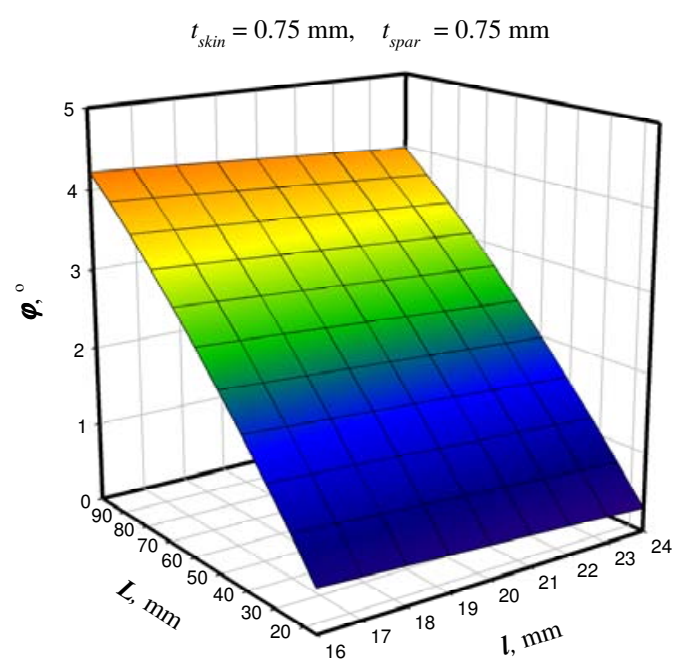

Fig 15. The dependencies of torsion angle on MFC chord-wise length and spar circular fitting

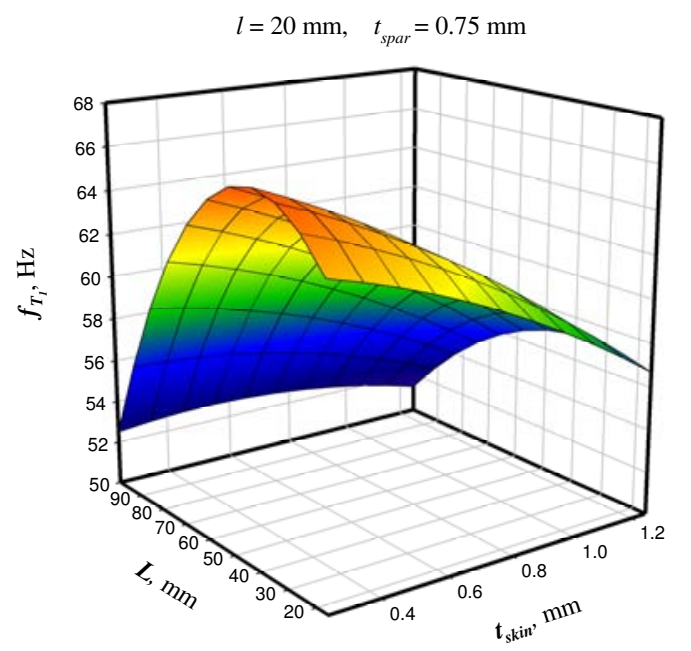

Fig 16. The dependencies of first torsion frequency on MFC chord-wise length and skin thickness

The dependencies of the location of the centre of gravity on MFC chord-wise length and skin thickness are given in figure 17 . 


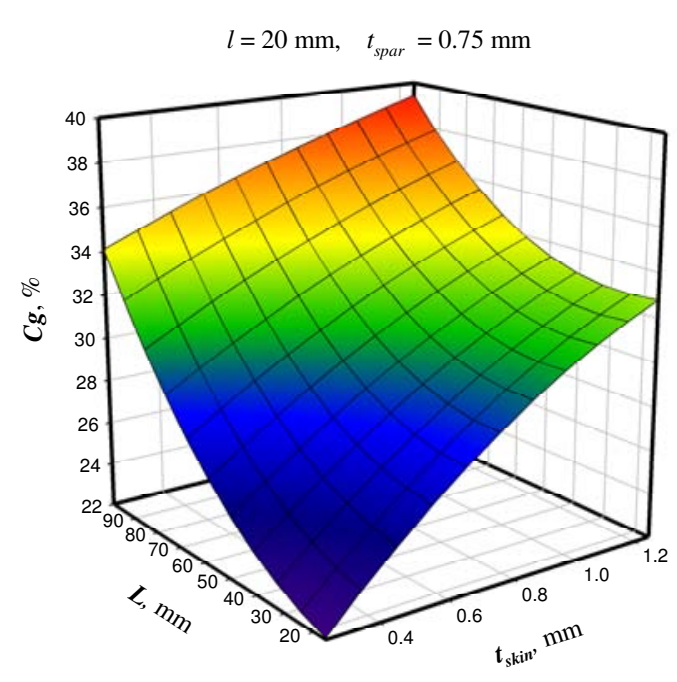

Fig 17. The dependencies of gravity location on MFC chordwise length and skin thickness

\section{Conclusions}

An optimisation problem for the optimum placement of actuators in helicopter rotor blades has been formulated on the results of parametric study using the finite element method.

The methodology, based on the planning of experiments, the response surface technique, and parametric study, has been developed for the optimum placement of actuators in helicopter rotor blades. To describe the behaviour of a twisted rotor blade, the finite element method has been applied in the sample points of experimental design. For this purpose the structural static analysis with a thermal load, using a 3D finite element model, has been developed by ANSYS. The Improved Multicast Random Search, using the approximating functions instead of the original functions, has solved minimisation problems.

From the optimisation results of the present study, and in comparison with previous studies, it was observed that the 2nd variant arrangement of MFC is more effective than the $1^{\text {st }}$ in the production of a maximum torsion angle under voltage on $26 \%$.

From the approximation function and using the obtained optimal results there can be found a compromise between the necessary solutions.

\section{Acknowledgements}

The Latvian Ministry of Education and Science, project No. 7061, supports this research work.

\section{References}

1. AUZINS, J. Direct optimisation of experimental designs. In The 10th AIAA/ISSMO Multidisciplinary Analysis and Optimisation
Conf, AIAA paper. 2004, no. 2004-4578, p. 1-22.

2. BERHARD, CHOPRA, I. Analysis of a bending-torsion coupled actuator for a smart rotor with active blade tips. Smart Material Structure, vol.10, p. 35-52, 201.

3. BERHARD, CHOPRA, I. Hover testing of active rotor blade tips using a piezoinduced bending-torsion coupled beam. Intelligent Material System Structure. 1998, vol. 9, p. 963-974.

4. CHEN, P., CHOPRA, I. Hover testing of smart rotor with induced-strain actuation of blade twist. AIAA proc. 1997, vol. 35, p. 6-16.

5. CHEN, P., CHOPRA, I. Induced strain actuation of composite beams and rotor blades with embedded piezoceramic elements. Smart Material Structures. 1996, vol. 5, p. 35-48.

6. EGLAIS, V. Approximation of data by the multi-dimensional equation of regression. In Problems of Dynamics and Strength. Edited by E. Lavendel. 1981, vol 39, p. 120-125.

7. JANUSEVSKIS, A., AKINFIEV, T., AUZINS, J. et al. A comparative analysis of global search procedures. Proceedings of the Estonian Academy of Science, Vol 10, No. 4, p. 236-250, 2004.

8. KOVALOVS, A., BARKANOV, E., GLUHIHS, $\mathrm{S}$. Active twist of model rotor blades with $\mathrm{D}$ spar design. Transport. 2007, vol. XXII-1, p. 38-44.

9. KUHN, P. Remarks on the elastic axis of shell wings. National Advisory Committee for Aeronautics. Washington: Technical Notes, Apr. 1936, no. 562, p. 12.

10. PARK, J-S., KIM, J-H. Analytical development of single crystal macro fiber composite actuators for active twist rotor blades. Smart Materials and Structures. 2005, vol.14, p. 745-753.

11. RODGERS, JP., HAGOOD, NW. Design, manufacture and hover testing of an integral twist-actuated rotor blade. In Proceedings of the $8^{\text {th }}$ International Conference on Adaptive Structures and Technology. 1997, p. 63-72.

12. SODANO, HA., PARK, G., INMAN, DJ. An investigation into the performance of macrofiber composites for sensing and structural vibration application. Mechanical Systems and Signal Processing. 2003, vol. 18, p. 683-697.

13. WICKRAMASINGHE, VK., HAGOOD, NW. Material characterization of active fiber composites for integral twist-actuated rotor blade actuation. Smart Material Structures. 2004, vol. 13, p. 1155-1165.

14. WILLIAMS, BR., PARK, G., INMAN, DJ. et al. An overview of composite actuators with piezoceramic fibers. Smart Material Structures. In Proceedings of the 20th International Modal Analysis Conference. 2002. Available at www.smart-material.com 